\title{
Female Stress Urinary Incontinence Treatment by Forming an Uretro-Vesical Angle with or without Mesh
}

\author{
Mehmet Kilinc, Yunus Emre Göger \\ Department of Urology, Meram Medical Faculty, Necmettin Erbakan University, Konya, Turkey \\ Email: mehmkilinc@hotmail.com
}

How to cite this paper: Kilinc, M. and Göger, Y.E. (2017) Female Stress Urinary Incontinence Treatment by Forming an Uretro-Vesical Angle with or without Mesh. Open Journal of Obstetrics and Gynecology, 7, 182-192.

https://doi.org/10.4236/ojog.2017.72020

Received: December 15, 2016

Accepted: February 6, 2017

Published: February 9, 2017

Copyright $\odot 2017$ by authors and Scientific Research Publishing Inc. This work is licensed under the Creative Commons Attribution International License (CC BY 4.0).

http://creativecommons.org/licenses/by/4.0/

\begin{abstract}
Objective: To evaluate, in a comprehensive way, mesh and mesh free SUI treatment results obtained in a single center. The present study addresses the efficacy and safety of a novel surgical technique. Material \& Methods: Adult female SUI patients, 184 in total, were divided within a sequential manner into two groups to be treated for SUI either with or without mesh insertion during a surgical intervention. In this novel procedure, a vertical vaginal incision from the urethra towards the bladder bottom is made and closed transversely. After the intervention the patients revisited the clinic at the $6^{\text {th }}$ month. Results: 81 patients in mesh and 83 in the mesh free group completed the 2year follow up. Based on the pad tests conducted at the end of 24-month follow up, $82 \%$ of the patients in the mesh free group and $85 \%$ in the mesh group were considered as successful if the pad test resulted with $\leq 2$ gram. Cystocele of Grade I or II was also treated in 69 patients within the same single surgical procedure. Conclusion: The surgical outcomes of the mesh and mesh-free group were almost the same. However, though the cure rate of the mesh group was higher, it was not statistically significant. Adverse events were more frequent in the mesh group due to mesh presence.
\end{abstract}

\section{Keywords}

Female Incontinence, Stress Urinary Incontinence (SUI), Cystocele, Mesh, Treatment

\section{Introduction}

Worldwide women, with a prevalence of $25 \%$ - $57 \%$, suffer from varying degrees of stress urinary incontinence (SUI) [1] related complaints leading to the emergence of varying surgical techniques [2]. Possible underlying mechanisms are 
increasing urethral resistance [3] and/or relocating the proximal urethra to a more intra-abdominal position in order to optimize urethral pressure [4]. Recent procedures favor mid-urethral support rather than bladder repositioning to increase urethral resistance [5].

Conflicting reports on the impact of Burch colposuspension (BC) and pubovaginal slings (PVS) on urethral resistance have been published [4] with contradictory success rates such as similar discussions about the efficacy of mid-urethral sling (MUS) [6]. Tension vaginal tape (TVT) has been associated with some peri and post operative complications such as bladder perforation, temporary or persistent urinary retention, urinary infection, and de novo instability [7]. In order to avoid these complications, Transobturator tape (TOT) was proposed yielding roughly similar continence rates compared to retro-pubic TVT [8] [9] [10] [11] [12]. Besides, a needle suspension procedure for genuine stress incontinence and anterior vaginal wall prolapse was developed and applied during vaginal hysterectomy for anterior vaginal wall relaxation correction [13]. In the present study, we describe a novel vaginal technique to treat female SUI and if present also cystocele Grade I - II, regardless being symptomatic, within the same surgical intervention. In this procedure the urethra-vesical junction (UVJ) angle, much larger before the operation, is narrowed with a surgical intervention. Sub-urethral incision is continued to sub-vesical vaginal vertically and closed transversely either with or without mesh according to the patient groups. This surgical technique, with or without mesh, is feasible, accurate, quick, and simple while preserving the urethra and bladder.

\section{Material \& Method}

Throughout April 2002 to May 2012, 184 women were in a sequential manner into two cohorts as propylene mesh $(2.5 \times 2.5 \mathrm{~cm})$ or mesh-free groups after obtaining their informed consent about their participation in writing. According to their groupings, patients were intervened within a sequence after obtaining the permission of the local ethic committee (Nr.2002). The mean age of the participants was 46.8 years old ranging between 32 and 78 . They were evaluated preoperatively with pad test, coughing test, urodynamic (multichannel) test made using urethral pressure profilometry (UPP) voiding pressure study, and clinical examination. Exclusion criteria were former pelvic and vaginal surgery history within the last 6 months, urethral and/or bladder pathologies, active urinary tract infection (UTI), refractory overactive bladder, and grade 3, 4, and 5 anterior and/or posterior prolapse.

The degree of pelvic organ prolapse was evaluated using Baden Walker et al. criteria [14] during the physical examination. In the present study, SUI patients with Grade I \& II anterior cystocele were treated for cystocele within the same surgical intervention. The one hour pad test was a routine evaluation process for SUI. An increase of less than 2 gram in the total pad weight is considered as normal, 2 - 10 gram as mild, 10 - 50 gram as middle, and above $50 \mathrm{gr}$ as severe incontinence in the pre- and postoperative SUI evaluation. This test, used while 
determining the success of the intervention, is considered to be practical and useful in determining the leakage amount [15].

Urogenital Distress Inventory (UDI-6) and Incontinence Impact Questionnaire (IIQ-7) short form symptom scores in SUI patients and urodynamic evaluation were a part of the total evaluation process. Invasive Urodynamic test was performed using double lumen catheter. Rectal tube was used to record abdominal pressure while voiding in sitting position with the catheter. Incontinence was graded according to McGuire et al. [16] test conducted at $200 \mathrm{ml}$, as I if the abdominal pressure was leak point pressure (LPP) $>90 \mathrm{~cm} \mathrm{H}_{2} \mathrm{O}$, as II if LPP was $60-90 \mathrm{~cm} \mathrm{H}_{2} \mathrm{O}$, and as III if LPP was $<60 \mathrm{~cm} \mathrm{H}_{2} \mathrm{O}$. The patients were asked to strain during cystometry until leakage was detected.

\section{Surgical Technique}

The aim of the surgical procedure was to decrease the urethra-vesical junction (UVJ) (bladder neck) angle either with or without mesh in 184 selected patients according to their grouping. Patients were examined in dorsal lithotomy position and were tested for incontinence under general or regional anesthesia by injecting $400 \mathrm{ml}$ Saline solution into the bladder via a 16 Foley catheter. After the removal of the catheter, first Boney-Marchetti test was applied. Subsequently Q-tip test was made. Finally, in order to determine urinary leakage the self designed technique in which suprapubic abdominal pressure on the bladder using fingers was applied. This test was designed by the researcher to determine urinary leakage before and after the beginning of the surgical intervention.

Foley catheter is reinserted and a balloon is inflated both to empty the bladder and to initiate the procedure. Upon emptying bladder, a small transverse incision is made $5 \mathrm{~mm}$ below the urethral meatus to prevent meatus perforation with electrocautery at small dozes. Then the bladder UVJ is marked using electrocautery if this part yields in with pressure. Female urethra is hard and does not yield in with pressure. A vertical suburethral vaginal incision about $2.5 \mathrm{~cm}$ is made from the small transverse incision until UVJ. Later on an incision of the same size is made from the UVJ to the vaginal bladder bottom. In the presence of cystocele of Grade I - II, the vaginal bladder bottom incision is continued downwards up to $1-1.5 \mathrm{~cm}$. In this technique only the vaginal tissue is incised until periurethral and perivesical fascia.

First 2/0 vicryl absorbable sutures 3 - $4 \mathrm{~mm}$ approximately above and under of UVJ (bladder neck) are passed and thus the first line is formed transversely (about 5 sutures one in the urethral middle and 2 to both left and right) (Figure $1(\mathrm{a}))$.

If folded propylene mesh $(2.5 \times 2.5)$ is to be used, it is placed under the first line (Figure 1(b)). Then the second line is formed using 4/0 non-absorbable prolene sutures (Figure 2) and the third line with $2 / 0$ vicryl absorbable sutures in the same way (Figure 3(a)). The vaginal tissue incised vertically until urethral and vesical fascia is finally closed transversely (Figure 3(b)).

Following the intervention, the bladder is filled with $400 \mathrm{ml}$ saline solution 


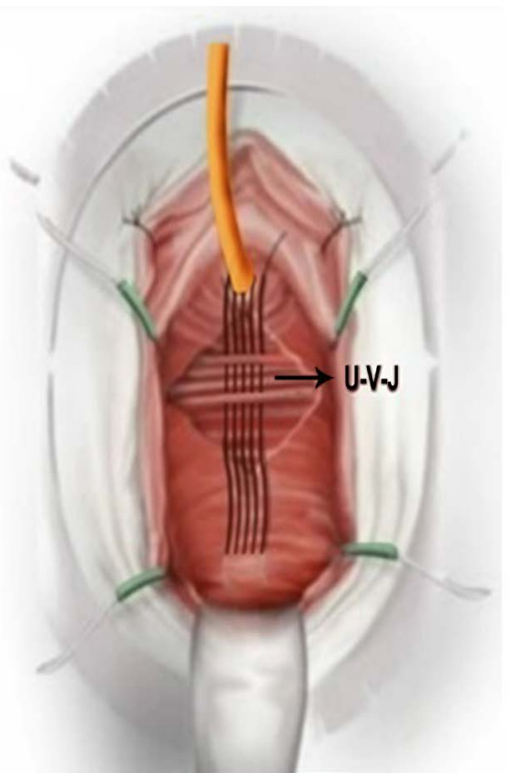

(a)

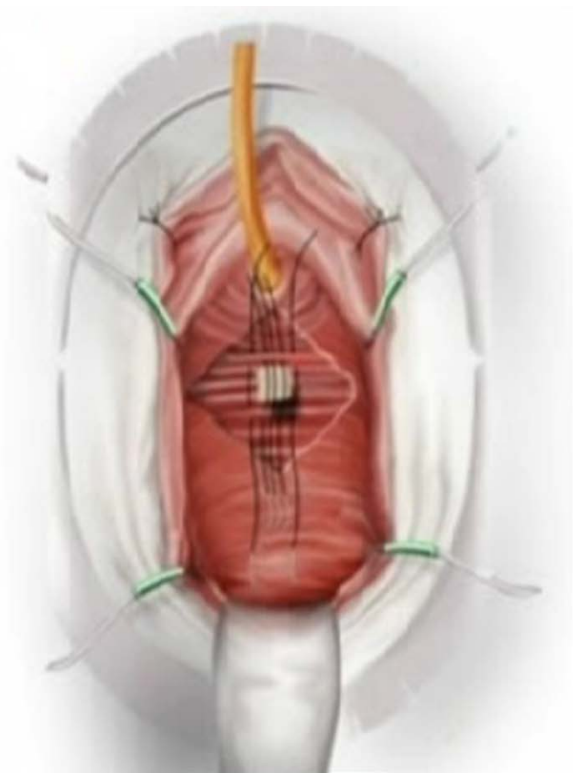

(b)

Figure 1. Urethro-vescial junction angle-formation: (a) First-line vicryl sutures (no mesh), (b) First-line mesh then vicryl sutures.

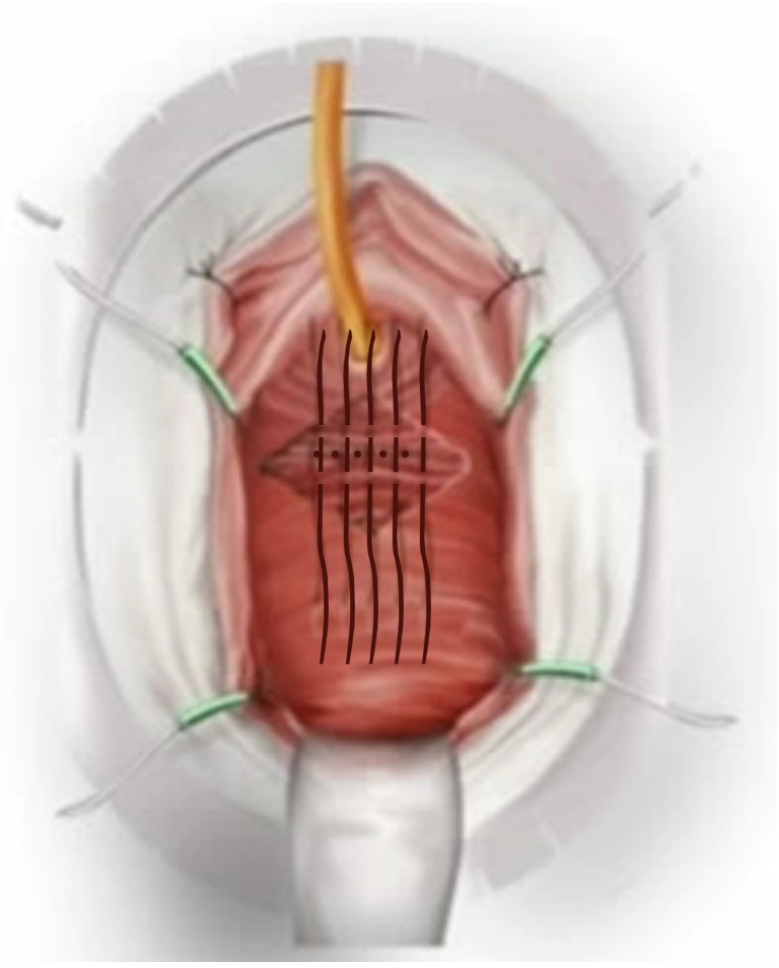

Figure 2. Urethro-vescial junction angle-formation: second-line 1 prolene sutures.

and the Foley catheter inserted earlier is removed. Boney-Marchetti test, Q-tip test, and suprapubic abdominal pressure (to the upper bladder area) to determine urethral leakage by using fingers are made upon surgical intervention. The surgical intervention is considered successful if there is no leakage in the Boney-Marchetti test and abdominal pressure test. Whether the Q-tip test may be 


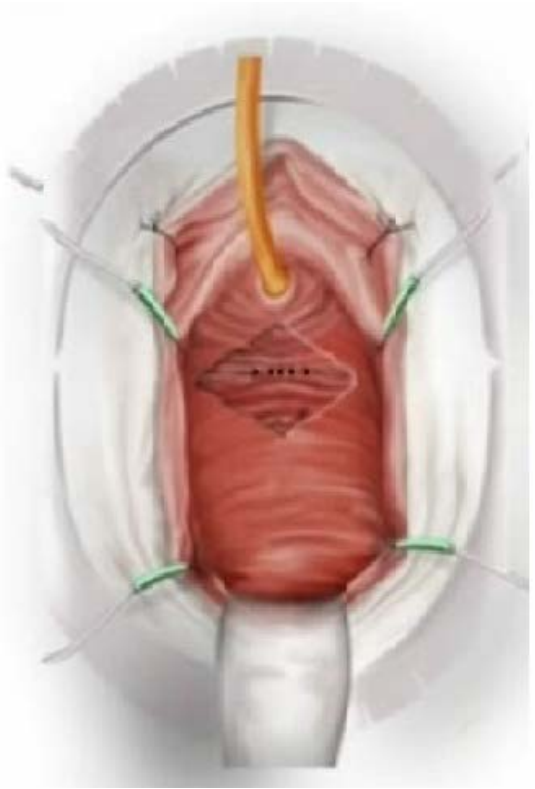

(a)

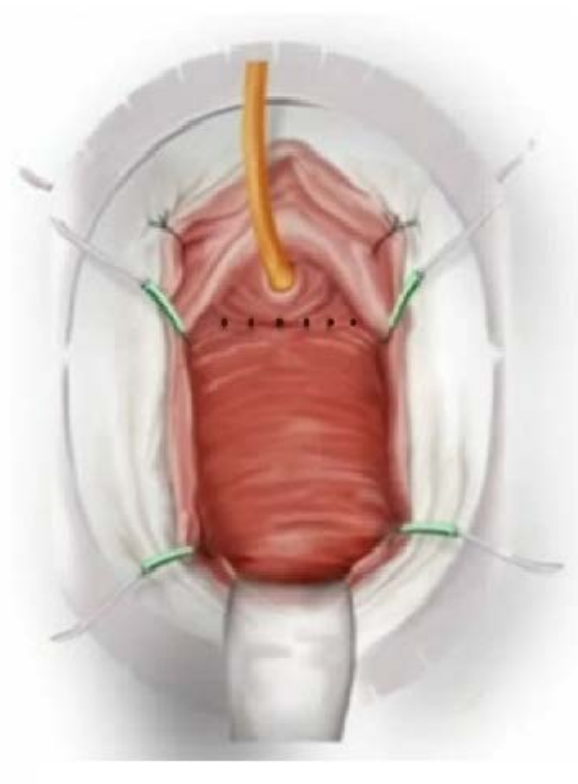

(b)

Figure 3. Urethro-vescial junction angle-formation: (a) Third-line vicryl sutures, (b) Transverse vaginal closure.

positive or not, incontinence may not be present in all cases. Q-tip test can be positive in bladder neck elevation and urethral mobility. Later on, during cystopic examination the bladder neck is seen to be as elevated and closed.

The 16-Foley is reinserted and totally removed during the $1^{\text {st }}$ or $2^{\text {nd }}$ post operative day. Following catheter removal, patients are discharged. In the comparison of mesh and mesh free groups, Chi-square test was used. Independent t-test, Mann Whitney U-test and Fischer exact test were employed to evaluate patient parameters and urodynamic results of both groups. In all statistical analyses, $\mathrm{p} \leq$ 0.05 was considered as the threshold level for statistical significance. For statistical analyses Statistical Package for the Social Sciences (SPSS) (version 15, Chicago Illinois) package program was used.

\section{Results}

The mean age of the 81 patients in the mesh and 83 patients were in the meshfree group was $46.8(32-78)$. These participated in the 24 month postoperative follow up period throughout April 2002 to May 2012 period. During the postoperative follow up period 9 patients in the mesh and 11 in the mesh-free group were lost. There was no statistically significant difference in terms of mean age and Body Mass Index (BMI) (Table 1).

Total prolapse (anterior/posterior) (POP) prevalence was 83. In 34 patients out of 81patients in the mesh group was anterior Grade I - II, and in 35 out of the 83 patients in the mesh free group it was anterior Grade I - II. Posterior POP number was in total for both groups 14 (Table 1). None of the patients who underwent surgical intervention required concomitant procedures for additional vaginal repair surgery such as pelvic organ prolapse as this technique repairs 
Table 1. Demographics and baseline evaluation of two groups.

\begin{tabular}{cccc}
\hline & Mesh & Mesh free & p Value \\
\hline Patients & 81 & 83 & \\
Age & $46.8(33-75)$ & $46.08(32-78)$ & 0.4 \\
BMI & $34.01 \pm 5$ & $31.99 \pm 5$ & 0.4 \\
POP Total Number & 42 & 41 & \\
& 34 & 35 & 0.3 \\
Anterior POP Grade I Grade II & 6 & 7 & 0.3 \\
& 26 & 28 & 0.3 \\
Posterior POP & 8 & 6 & 0.3 \\
Abdominal LLP & $90 \pm 23$ & $81 \pm 27$ & 0.5 \\
& & & 0.5 \\
Grade of SUI Grade I Grade II Grade III & 20 & 23 & 0.5 \\
\hline
\end{tabular}

cystocele Grade I - II together with SUI. The patients were divided preoperatively according to their abdominal LLP in different SUI grades as SUI Grade I, II, and III. Patients with SUI Grade II were more common (Table 1). Pad test is employed to determine surgical outcomes and to determine success throughout the 24 month postoperative period.

In none of the patients, intra-operative urethral and/or bladder perforations emerged. This is an advantage of the present technique. Among sexually active women, none experienced dyspareunia and felt suture or mesh related discomfort except for mesh and/or prolene extrusion and erosion. Intra-operative blood loss was less than $100 \mathrm{ml}$. Urinary tract infection (UTI) was the same for both groups and was treated with antibiotics disregarding urine culture. A further advantage of this surgical intervention is that both SUI and cystocele Grade I - II are treated within the same session. This fact makes this technique superior to MUS, PVS, BC, and the other surgical interventions in SUI treatment.

Mesh related early and late adverse events included erosion and/or prolene suture (4 patients) exposure and/or prolene suture ( 3 patients). Prolene suture visibility of non-absorbable prolene suture was seen in 4 patients in each group. Mesh extrusion and vaginal erosion, especially prolene suture was felt mostly through the anterior vaginal wall by the patients within the $3-6$ months of the postoperative period. These conditions do not have an impact on SUI treatment.

Vaginal epithelium perforation occurred in 2 patients in each group. Postoperative catheter use for more than 3 days was necessary in 3 patients in the mesh group and in 2 patients in the mesh-f1ree group. Novo urgency was seen in 3 patients in the mesh group and 2 patients in the mesh free group. All these 5 novo urgency cases responded to medical treatment.

Baseline and post operative $6^{\text {th }}$ month urodynamic parameters of SUI patients 
were evaluated. Although the abdominal leak point pressure (LLP) is higher in the mesh group, this difference between two groups is not statistically significant. On comparing the baseline level and at postoperative $6^{\text {th }}$ month data, post-voiding residual urine (PVR) levels had slightly increased (mesh group $4 \pm$ $5 \mathrm{ml}$ and mesh free group $3 \pm 5 \mathrm{ml}$ ); however, cystometric capacity, compliance, Q-max results had, as a result of the treatment modality, decreased (Table 2). Yet, these outcomes were not statistically significant $(\mathrm{p} \leq 0.05)$. In the two groups, 4 patients in total had de novo urgency and were therefore treated with anticholinergics.

Preoperative and postoperative Short Incontinence Impact Questionnaire (IIQ-7) and Urogenital Distress Inventory (UDI-6) results for both groups are presented as baseline and postoperative 6 months results. During the 6 months follow up, mesh and mesh free groups showed statistically significant decreases compared to the pre intervention levels $(\mathrm{p} \leq 0.05)$ (Table 3 ).

Pad test results indicated that at the end of 24 month follow up, $82 \%$ of the patients in the mesh free group and $85 \%$ in the mesh group were cured. However, based on the 1-hour pad test ( $\geq 2 \mathrm{mg}$ ) 13 patients in the mesh group and 14 patients in the mesh free group were considered as failures. Comparing the mesh free and mesh group in terms of the data obtained in the present study, there differences among the both groups were not of utmost importance. Hence, due to the limited number of complications and simplicity of the surgical intervention the mesh free technique should be preferred.

Table 2. Comparison of postoperative urodynamic variables.

\begin{tabular}{|c|c|c|c|}
\hline & Mesh & Mesh Free & p Value \\
\hline PVR & $4 \pm 5 \mathrm{ml}$ & $3 \pm 5 \mathrm{ml}$ & 0.5 \\
\hline \multicolumn{4}{|c|}{ P Detrusor filling $\mathrm{cm} \mathrm{H}_{2} \mathrm{O}$} \\
\hline Baseline & $9 \pm 4$ & 8,5 & 0.5 \\
\hline 6 months & $9 \pm 4$ & $8 \pm 4$ & 0.5 \\
\hline \multicolumn{4}{|c|}{ Compliance $\mathrm{ml} / \mathrm{cm} \mathrm{H}_{2} \mathrm{O}$} \\
\hline Baseline & $84 \pm 50$ & $70 \pm 49$ & 0.4 \\
\hline 6 months & 67 & 75 & 0.4 \\
\hline \multicolumn{4}{|c|}{ MCG (ml) } \\
\hline Baseline & $381 \pm 100$ & $377 \pm 110$ & 0.3 \\
\hline 6 months & $335 \pm 100$ & $309 \pm 100$ & 0.3 \\
\hline \multicolumn{4}{|c|}{$P$ Detrusor $\mathrm{Q} \max \mathrm{cm} \mathrm{H}_{2} \mathrm{O}$} \\
\hline Baseline & $25 \pm 11$ & $28 \pm 13$ & 0.3 \\
\hline 6 months & $27 \pm 14$ & $28 \pm 11$ & 0.4 \\
\hline \multicolumn{4}{|c|}{$\mathrm{Q} \max$} \\
\hline Baseline & $20.5 \pm 8$ & $19.6 \pm 7$ & 0.5 \\
\hline 6 months & $18 \pm 8$ & $18 \pm 8$ & 0.5 \\
\hline
\end{tabular}

Independent t-test, Mann Whitney U-test, Fischer exact test. 
Table 3. Pre and postoperative values of short incontinence impact questionnaire (IIQ-7) and Urogenital Distress Inventory (UDI-6).

\begin{tabular}{cccc}
\hline & Mesh & Mesh Free & p Value \\
\hline Uaseline & UDI-6 & & \\
Postop. 6 months & $14 \pm 13$ & $42 \pm 11$ & 0.04 \\
& IIQ-7 & $14 \pm 12$ & 0.04 \\
Baseline & $43 \pm 12$ & $41 \pm 12$ & 0.04 \\
Postop. 6 months & $16 \pm 11$ & $16 \pm 12$ & 0.04 \\
\hline
\end{tabular}

\section{Discussion}

The main objective of SUI surgical treatment is to render patients completely continence without significant morbidity. Following the first report of Ulmsten et al. [17] on a new SUI surgical treatment modality, Gynaecare's TVT gained global diffusion due to minimal invasive and high success rates. Many other devices are now on the market. In order to minimize retropubic space injury, TOT has been used to place the sling both with outside-in and inside-out approachesas proposed by Delorm [10] [18] and by Leval [2]. Many retrospective studies have shown that the difference between inside-out TOT and outside-in TOT approaches was insignificant [19]. The authors concluded that both of these approaches were equally safe and clinically effective. Another randomized prospective study, [20] compared TVT and TOT patients, and did not determine a significant difference in terms of objective cure rate [21]. In our study, no significant difference in the objective cure rates of the patients in both groups (objective cure rate of the mesh group $85 \%$ and of the mesh free group $82 \%$ at the end of 24 month follow up). Teo et al. [22] found that cure rates for TVT patients at 1 year $85.4 \%$ and for TOT $89.7 \%$ at the same time interval. Accumulating reports have indicated the efficacy of tension-free sub-urethral tapes which are currently widely utilized [2].

Kraus et al. [22] compared SUI treatment using BC and PVS. Only patients with fascial sling had significant increase in detrusor pressure at maximum flow, suggesting increased outlet resistance. Zullo et al. [23] have found no significant decrease in non invasive urine flow rates, PVR, and P detrusor Q max. In the present study, except mesh originating problems, there were no significant complications in both groups. The results of randomized prospective multi-center studies trial comparing retropubic TVT with colposuspension, have recently shown that continence rates were similar at 6 month follow up [18] [24]. TVT procedure required much less operative time, short hospitalization, less post operative pain, faster return to normal daily activities than BC. The current procedure, with a mean operative time about 30 minutes, aims to narrow UVJ angle with plication sutures in order to achieve natural hammock effect.

The position of TOT, TVT tape, and PVS is similar to that of the natural hammock supporting the urethra [25] and the natural hammock supporting the 
bladder neck in PVS. Our technique forms an angle in the urethra-vesical junction in both the mesh and mesh free patient with plication sutures. This condition increases the hammock effect in the bladder neck as described by De Lansey [25] [26].

Boustead [7] have reported serious complications such as vascular and bowel injuries, in addition to bladder perforation, de novo urgency in $2.5 \%-25 \%$, urinary retention in $1.5 \%-12 \%$, and hematoma. In the present surgical technique major complications were not observed; yet, de novo urgency developing were cured using anti-muscarinic drugs yielding satisfactory responses. Urine retention and PVR in both groups was less than $100 \mathrm{ml}$. However, the difference between the two groups was not significant. In the present study vaginal erosion and/or prolene suture visibility, and vaginal mesh exposure and/or prolene suture visibility are the most common complications in patients with folded mesh SUI treatment. Whereas, prolene suture visibility is common in the mesh free group, mesh related problems arouse in the folded mesh group. We did not observe any cases of urethral and/or bladder perforation.

\section{Conclusions}

In conclusion, the comparison of the mesh and mesh free group indicated that the mesh free SUI treatment is safer because of the missing mesh related complication.

The surgical procedure described is safe, simple, accurate, as it preserves the bladder and urethra. Moreover, in the presence of cystocele Grade I - II, it is treated within the same session.

The findings of the present study propose an alternative to various mid urethral slings in female SUI treatment. However, the necessity for prospective studies with higher patient series in female SUI treatment constitutes a limitation of the present study.

\section{Acknowledgements}

We would like to express our gratitude to Dr. Osman Ergün, and to Dr. Harun Şimşek for their support in general, statistical analysis, and for English revision.

\section{Ethical Standards}

The present study has been conducted according to decision of the local ethics committee of Selçuk University enumerated 2002.

\section{Conflict of Interest}

The author declares no conflict of interest.

\section{Authors' Contributions}

The present study is conducted by a single author. The minor contributions of the colleagues are expressed in the acknowledgment section. 


\section{References}

[1] Haylen, B.T., de Ridder, D., Freeman, R.M., et al. (2010) An International Urogynecological Association (IUGA)/International Continence Society (ICS) Joint Report on the Terminology for Female Pelvic Floor Dysfunction. International Urogynecology Journal, 21, 5-26. https://doi.org/10.1007/s00192-009-0976-9

[2] Leval, J.P. (2003) Novel Surgical Technique for the Treatment of Female Stress Urinary Incontinence: Transobturator Vaginal Tape Inside-Out. European Urology, 44, 724-730. https://doi.org/10.1016/j.eururo.2003.09.003

[3] Klutke, J.J., Klutke, C.G., et al. (1999) Urodynamic Changes in Voiding after AntiIncontinence Surgery: An Insight into the Mechanism of Cure. Urology, 51, 1003 1007. https://doi.org/10.1016/S0090-4295(99)00354-4

[4] Belair, G., Tessier, J., Bertrand, P.E., et al. (1997) Retropubic Cystourethropexy: Is It an Obstructive Procedure? The Journal of Urology, 158, 533-538. https://doi.org/10.1016/S0022-5347(01)64529-4

[5] Ulmsten, U., Falconer, C., Johnson, P., et al. (1998) A Multicenter Study of Tension-Free Vaginal Tape (TVT) for Surgical Treatment of Stress Urinary Incontinence. International Urogynecology Journal, 9, 210-213. https://doi.org/10.1007/bf01901606

[6] Cholhan, H.J. and Lotze, P.M. (2004) Voiding Function after a Modified No-Tension Pubovoginal Sling. International Urogynecology Journal, 15, 249-256.

[7] Boustead, G.B. (2002) The Tension-Free Vaginal Tape for Treating Female Stress Urinary Incontinence. BJU International, 89, 687-693. https://doi.org/10.1046/j.1464-410X.2002.02659.x

[8] Wadie, B.S. and Elhefnawy, A.S. (2013) TVT versus TOT, 2-Year Prospective Randomized Study. World Journal of Urology, 31, 645-649.

https://doi.org/10.1007/s00345-012-0956-4

[9] Daher, N., Boulanger, J.C. and Ulmsten, U. (2003) Pre-Pubic TVT: An Alternative to Classic tvt in Selected Patients with Urinary Stress Incontinence. European Journal of Obstetrics, Gynecology, and Reproductive Biology, 107, 205-207. https://doi.org/10.1016/S0301-2115(03)00051-4

[10] Delorme, E. (2001) Transobturator Urethral Suspension: Mini-Invasive Procedure in the Treatment of Stress Urinary Incontinence in Women. Progres en Urologie, 11, 1306-1313.

[11] Droupy, S., De Tayrac, R. and Delorm, E. (2003) Transobturatorurethral Support for Female Stress Urinary Incontinence: 1 Year Outcome of a New Surgical Procedure. European Urology Supplements, 2, 197. https://doi.org/10.1016/S1569-9056(03)80781-9

[12] Hermieu, J.F., Messas, A., Delmas, V., Ravery, V., Dumonceau, O. and Boccon-Gibot, L. (2003) Plaie Vesicale Apres Bandelette Transobturator. Progrès en Urologie, 3, 115-117.

[13] Colakoğlu, M., Capar, M., Kilinc, M., Colakoğlu, U., Kaya, H. and Acar, A. (1996) A New Needle Suspension Procedure for Genuine Stress Incontinence and Anterior Vaginal Wall Prolapse. International Urogynecology Journal, 7, 64-68. https://doi.org/10.1007/BF01902374

[14] Baden, W.F., Walker, T.A. and Lindsey, J.H. (1968) The Vaginal Profile. Texas Medicine, 64, 5-58.

[15] Jargensen, L., Lose, G. and Andersen, J.T. (1987) One-Hour Pad Weighing Test for Objective Assessment of Female Urinary Incontinence. Obstetrics \& Gynecology, 69, 39-42. 
[16] Mc Guire, E.J., Cespedes, R.D. and O'Connell, H.E. (1996) Leak-Point Pressures. Urologic Clinics of North America, 23, 253-262. https://doi.org/10.1016/S0094-0143(05)70309-8

[17] Ulmsten, U., Henriksson, L., Johnson, P. and Varhos, G. (1996) Anambulatory Surgical Procedure under Local Anesthesia for Treatment of Female Urinary Incontinence. International Urogynecology Journal, 7, 81-86. https://doi.org/10.1007/BF01902378

[18] Liapis, A., Bakas, P. and Creatsas, G. (2002) Burch Colposuspension and TensionFree Vaginal Tape in the Management of Stress Urinary Incontinence in Women. European Urology, 41, 469-473. https://doi.org/10.1016/S0302-2838(02)00033-7

[19] Chae, H.D., Kim, S.R., Jeon, G.H., et al. (2010) A Comparative Study of Outside-In and Inside-Out Transobturator Tape Procedures for Stress Urinary Incontinence. Gynecologic and Obstetric Investigation, 70, 200-205. https://doi.org/10.1159/000318866

[20] Abdel-Fattah, M., Ramsey, J., Pringle, S., et al. (2010) Randomized Prospective Single-Blinded Study Comparing "Inside-Out" versus "Outside-In" Transobturator Tapes in the Management of Urodynamic Stress Incontinence: 1-Year Outcomes from the E-TOT Study. BJOG: An International Journal of Obstetrics \& Gynaecology, 117, 870-878. https://doi.org/10.1111/j.1471-0528.2010.02544.x

[21] Teo, R., Moran, P., Mayne, C. and Tincello, D. (2011) Randomized Trial of Tension-Free Vaginal Tape and Tension-Free Vaginal Tape-Obturator for Urodynamic Stress Incontinence in Women. Journal of Urology, 185, 1350-1355. https://doi.org/10.1016/j.juro.2010.11.064

[22] Kraus, S.R., Lemack, G.E., Sirls, L.T., et al. (2011) Urinary Incontinence Treatment Network: Urodinamic Changes Associated with Successful Stress Urinary Incontinence Surgery: Is a Little Tension a Good Thing? Urology, 78, 1257-1262. https://doi.org/10.1016/j.urology.2011.07.1413

[23] Zullo, M.A., Plotti, F., Calcagno, M., et al. (2007) One-Year Fellow-Up of Tension-Free Vaginal Tape (TVT) and Trans-Obturator Suburethral Tape from Inside to Outside (TVT-O) for Surgical Treatment of Female Stress Urinary Incontinence: A Prospective Randomized Trial. European Urology, 51, 1376-1382.

[24] Ward, K. and Hilton, P. and United Kingdom and Ireland Tension Free Vaginal Tape Trial Group (2002) Prospective Multicenter Randomized Trial of TensionFree Vaginal Tape and Colposuspension as Primary Treatment for Stress Incontinence. British Medical Journal, 325, 67.

[25] Beco, J., De Bischop, G., Dijkstra, R., Nelissen, G. and Mouchel, J. (1999) Perineology Reaching Equilibrium and Preserving It? Journal de Gynécologie Obstétrique et Biologie de la Reproduction, 28, 855-856.

[26] De Lancey, J.L. and Richardson, A.C. (1993) Anatomy of Genital Support. Clinical Obstetrics and Gynecology, 36, 19-33. 
Submit or recommend next manuscript to SCIRP and we will provide best service for you:

Accepting pre-submission inquiries through Email, Facebook, LinkedIn, Twitter, etc. A wide selection of journals (inclusive of 9 subjects, more than 200 journals)

Providing 24-hour high-quality service

User-friendly online submission system

Fair and swift peer-review system

Efficient typesetting and proofreading procedure

Display of the result of downloads and visits, as well as the number of cited articles Maximum dissemination of your research work

Submit your manuscript at: http://papersubmission.scirp.org/

Or contact ojog@scirp.org 